\title{
The most deadly disease of asylumdom: general paralysis of the insane and Scottish psychiatry, c. 1840-1940
}

\author{
G Davis \\ Wellcome Lecturer in the History of Medicine, School of History, Classics and Archaeology, University of Edinburgh, UK
}

\begin{abstract}
General paralysis of the insane (GPI) was one of the most devastating diseases observed in British psychiatry during the century after 1840, in terms of the high number and type of patients diagnosed, the severity of its symptoms and, above all, its utterly hopeless prognosis. With particular reference to the physicians and patients of the Royal Edinburgh Asylum, this article explores the diagnostic process and the social and medical significance of the 'death sentence' that accompanied the GPI diagnosis.
\end{abstract}

\author{
Correspondence to G Davis, \\ School of History, Classics and \\ Archaeology, University of \\ Edinburgh, Old Medical Quad, \\ Edinburgh, EH8 9AG, UK \\ tel. +44 (0) I3I 6508348 \\ e-mail Gayle.Davis@ed.ac.uk
}

KEYWORDS General paralysis of the insane, mortality, diagnosis, prognosis, postmortem, Royal Edinburgh Asylum

DECLARATIONS OF INTERESTS No conflicts of interest declared.

\section{INTRODUCTION}

General paralysis of the insane (GPI) emerged as a new and devastating form of insanity during the early nineteenth century. Its identification as a distinct disease category has been credited as the achievement of a small group of French psychiatrists, or alienists, as this profession was commonly known during the nineteenth century.' The disease was not recognised in Scotland until around $1839,{ }^{2}$ though clinicians on both sides of the English Channel questioned whether this was simply because British alienists had not yet 'learned to see' the disease. ${ }^{3,4}$

There was also considerable confusion as to the causation of GPI. Although the possibility of syphilis had been suggested as early as 1857 , this was not generally accepted in the nineteenth century, when the disease was thought to be multi-causal, relating largely to the destructive influences of the urban environment and in particular to the excesses of alcohol, tobacco and sex. Not until the early twentieth century did the 'syphilitic hypothesis' begin to achieve widespread acceptance, with the Japanese bacteriologist Hideyo Noguchi's demonstration of the presence of the organism, then called Spirochaete pallida, in the brain of a patient who had died of GPI. ${ }^{5}$ However, even then, Scottish asylum physicians continued to ascribe GPI to factors as diverse as 'bereavement', 'kick from a horse', and 'unknown origin'.

There was, however, broad agreement on the disease's symptomatology and prognosis. It was widely perceived as the most deadly disease of psychiatry. The course of
GPI was one of steady and progressive mental and physical deterioration ending in death. The disease inflicted degenerative dementia upon its sufferers in tandem with the development of muscular incoordination and paralysis, hence the disease's pseudonym 'dementia paralytica'. Most of those diagnosed were middle-aged males in the prime of their working lives; the socioeconomic implications of the disease were therefore a source of significant concern.Worst of all, there appeared to be no cure, the diagnosis conferring an almost certain death sentence upon its sufferers. As a result of the type of patient diagnosed, the severity of the symptoms and the hopeless prognosis, the eminent Scottish alienist Thomas Clouston described GPI as the 'most terrible of all brain diseases'?

Nor was this 'most terrible' affliction rare. By the later nineteenth century up to $20 \%$ of British male asylum admissions received the diagnosis. ${ }^{8}$ From the late $1840 \mathrm{~s}$ onwards, GPI was commonly diagnosed in Scotland's main cities, particularly in Edinburgh. At the Royal Edinburgh Asylum (REA), Scotland's largest asylum, general paralytics constituted up to $17 \%$ of admissions and $34 \%$ of deaths. ${ }^{2}$ It was not until the discovery of penicillin in the 1940s that diagnosis of and death from GPI began to decline in British asylums.

General paralysis of the insane has been surprisingly neglected by historians, particularly given its numerical importance within British asylums in the century before 1940 and the fact that its history has resonances for a range of debates within the social history of medicine. ${ }^{2,6}$ A disproportionate amount of attention has, however, 
been given to malarial therapy, widely regarded as the most successful form of therapy for this disorder, prior to penicillin. ${ }^{10,11}$

With particular reference to the alienists and patients of the Royal Edinburgh Asylum, this paper explores the social and medical significance of the 'death sentence' that accompanied the GPI diagnosis. First, it considers how alienists characterised GPI and how its gloomy prognosis dominated clinical perceptions of this disease and its patients. Second, it explores how alienists believed the disease's characteristic symptoms to be a troubling and inappropriate precursor to death. Finally, it examines how the perceived certainty of GPl's mortality shaped the diagnostic process within the asylum, stressing the importance of post-mortem findings to the 'final' diagnosis. It suggests that, while 'silting up' the Victorian and Edwardian asylum, the general paralytic may also have acted as a catalyst to Scotland's embracing of the German neuropsychiatric tradition.

\section{A COMPLEX AND CRUEL DISEASE}

When nineteenth-century alienists discussed GPI in print, which they did frequently, they tended to focus upon two characteristics of the disease: the nature of the relationship between mental and physical symptoms and the fatal prognostic implications. Until at least the 1870s, alienists in Britain and France actively negotiated the exact mental and physical parameters of the disease. $^{12}$ David Skae (Physician-Superintendent of the REA from 1846 to 1873 ) preferred to view the disease as a form of paralysis complicated with insanity; ${ }^{13}$ whereas Harington Tuke considered it 'unphilosophical' to omit insanity from the fundamental definition of the disease. ${ }^{14}$ However, as Skae and Thomas Clouston (REA superintendent between 1873 and 1908) collectively concluded, the question of whether GPI was 'paralysis complicated with insanity, or a form of insanity complicated with paralysis' was 'a mistake entirely'. While it might begin as either, it was 'always both at the end' of the patient's life, assuming that the patient lived long enough for the disease to run its full course. ${ }^{15}$

Alienists increasingly agreed that these two groups of phenomena - paralysis and insanity - were the associated symptoms of a definite disease entity rather than a mere complication. This claim was based upon the 'predictable' clinical natural history of the disease, but more so on its 'distinctive' brain pathology. While GPI's high death rate theoretically provided much material for the asylum pathologist, heated debates continued over the disease's pathology amidst highly variable post-mortem rates in British asylums. Thus, one London-based lecturer in psychological medicine lamented the fact that 'every portion' of the paralytic's brain had 'been thought to be the part affected', yet no 'morbid appearance' had as yet been found to be 'pathognomic of the disease', since such lesions had 'been found to exist in the brains of other insane patients, or even in the brains of those not insane'. ${ }^{16}$ Both Skae and Clouston considered GPI to be a pathologically distinct disease and devoted considerable asylum resources to proving this.

Alienists were at least agreed in their descriptions of the disease's symptomatology and outcome. By the midnineteenth century, medical textbooks provided a consistent but lengthy list of the physical and mental symptoms considered characteristic of GPI. The disease generally progressed through three stages. ${ }^{17}$ In the first, patients would exhibit slight defects of speech, uncoordinated facial muscles, eye irregularities and mental exaltation. Unless the patient died of exhaustion or convulsions, he would be expected to pass into the second stage, characterised by increased muscular incoordination, paralysis and mental enfeeblement. The final stage was said to be one of fairly complete paralysis and 'mental extinction', the complete loss of intellectual and physical functions culminating in certain death.

While the inevitability of death was generally accepted, Skae and Clouston differed in their views as to the cause. Skae believed that death might occur during an epileptic or apoplectic seizure, which was commonly observed in patients nearing the end of the disease, but was more frequently due to 'the supervention of other diseases' such as phthisis or diarrhoea. ${ }^{13}$ For Clouston, while patients might asphyxiate during a seizure, or die from another cause such as acute lung disease, exhaustion was believed to be the usual cause of death. ${ }^{17}$ It might be noted, therefore, that cases are likely to be overlooked if we consider merely the asylum admission and death rates attributed specifically to GPI.

Into the early twentieth century, alienists continued to display a morbid fascination for the disease. For Scottish physicians, in terms of its frequency and gravity GPI remained 'one of the most terrible maladies that can afflict a human being', being 'fatal, with rare exceptions, within a few years'. ${ }^{18}$ In 1904 alone, the total number of deaths from GPI in the Scottish asylums was stated to be I,795 with approximately 2,250 deaths in England. ${ }^{19}$ Clouston's successor, George Robertson (REA superintendent 1908-1932), noted on the eve of the Great War that GPI remained 'as desperate a disease as any cancer, for 50 per cent of those suffering from it die[d] in one year, 75 per cent in two years and 90 per cent in three years, and the existence of the few who survive[d] this period [was] a living death'. ${ }^{20}$

The chronic and fatal nature of GPI and the intensive nursing care which it consequently required meant that it took up a disproportionate amount of asylum 
resources. This was especially unwelcome in a period of acute fear relating to the perceived 'remarkable increase' in the British asylum admission rate, ${ }^{21}$ particularly of the chronic insane and the consequent 'silting up' of asylumdom. ${ }^{22}$ Moreover, amidst widespread 'race suicide' concerns, with the British birth rate in decline and the loss of soldiers in combat, the social epidemiology of the disease was a source of further concern. It was not simply the number of patients dying but the type. The majority of general paralytics admitted to the Scottish asylums in the half century after 1880 had been gainfully employed in working class occupations that included butchers, clerks, domestic servants and miners. The average age of the general paralytic upon admission to the REA was 42 and male GPI admissions outnumbered females by a ratio of $5: 1 .^{23}$ In short, as the institution's annual reports stated, it was 'not the weaklings and the worthless' that GPI killed, but 'the most active and energetic'. ${ }^{24}$ Since most of those diagnosed were middleaged men in the prime of their working lives, the significant numbers afflicted and the grave prognosis had deeply worrying implications. Desperate remedies, including malarial therapy, were thus embraced enthusiastically, for, as one physician argued, 'to contemplate with arms folded a patient with general paralysis is to enter into a compact with Death'. ${ }^{25}$

\section{A TROUBLING APPROACH TO DEATH}

The number of patients affected, the type of patient and the speed with which most succumbed to the disease were cause for concern for nineteenth- and early twentieth-century alienists. Perhaps even more disturbing was the symptomatology displayed by the patients as death approached. Thomas Clouston highlighted the leading features of GPI as 'mental enfeeblement and mental facility', 'delusions of grandeur and ideas of morbid expansion or self-satisfaction'. ${ }^{26}$ It was the very contrast between these two simultaneous elements - utter facility and wild grandiosity - that alienists considered poignant, worrying, and downright inappropriate.

One of the key symptoms associated with GPI was the peculiar form of mania referred to by some authors as 'mania paralytica'. While other forms of GPI were recognised, including the 'depressed' form, the 'manic' form was commonly referred to as the 'classical' type because it was the first recognised and most common. It was characterised by a maniacal attack that involved intense feelings of joy and delusions of grandeur. The patient might believe that he was God or royalty, or that he possessed millions of pounds, many wives, businesses or talents. Many of those diagnosed as general paralytic within the REA exhibited such symptoms, including WM, a 44-year-old married patient, whose case notes state that he claimed to have "married 500 women or "slept 80 hours" nearly every morning; he speaks all the languages; in fact he "made" them; then he mutters inarticulately and calls it Japanese'. ${ }^{27}$ Indeed, so characteristic of GPI were such delusions considered to be that physicians felt it necessary to draw attention to their absence in patients believed to be general paralytics. Thus, JR, a 45-year-old married ship's captain, was described as 'a case of GP without the usual expansive delusions'. ${ }^{28}$

For authors such as David Skae, such delusions tended to indicate the patient's weakness of mind and lack of insight into his own condition. They could be contrasted, rather pathetically, with the reality of the situation. Thus, Skae wrote:

...in the midst of all this imaginary power and grandeur, he is... docile and facile.... Not unfrequently, while the conversation appears still rational, and any foolish act of extravagance has an ingenious explanation, the person will be found to be accumulating in his pockets or desk bits of glass or trash of various kinds, under the belief that they are precious stones. ${ }^{13}$

Skae considered this contrast a grotesque feature of the disease. He rebuked medical writers and poets for having focused too much upon patients labouring under phthisis. In that disease there were 'commonly early warnings of the insidious malady, and the patient [was] in some measure prepared for its development'; the consumptive mind might 'remain clear and unclouded to the last', and 'the light of life [went] out with some degree of splendour'. In the case of the paralytic, while it might be 'consolatory to think that the sufferer [was] unconscious of his condition', it nonetheless added 'painfully to the features of the disease, to see so much boasted grandeur and wealth associated with so much physical and mental degradation'.13

In their jointly authored Morisonian Lecture for 1873 , Skae and Clouston continued to stress this theme. They contrasted the 'high [professional] position' and 'unexampled industry' of the 'victim', seized 'in the prime and vigour of life', with the 'rapid decay' of the patient in their care, during which he would be 'insensible to all the ills of life, the grief of friends, the ruin of his hopes'. ${ }^{15}$ The REA alienists described the tragedy of such a patient who, 'on the brink of the grave', 'stagger[ed] about boasting of his wealth and grandeur', such as the paralytic who promised a 'dukedom or bishopric' to imbecile companions and was 'diverted from the highest enterprise or the most important duty by the simplest request'. For the majority of asylum patients there was a distinct hope of recovery. For some others, there was at least a realisation of death's proximity and opportunity to prepare oneself. Those considered chronically ill, most 


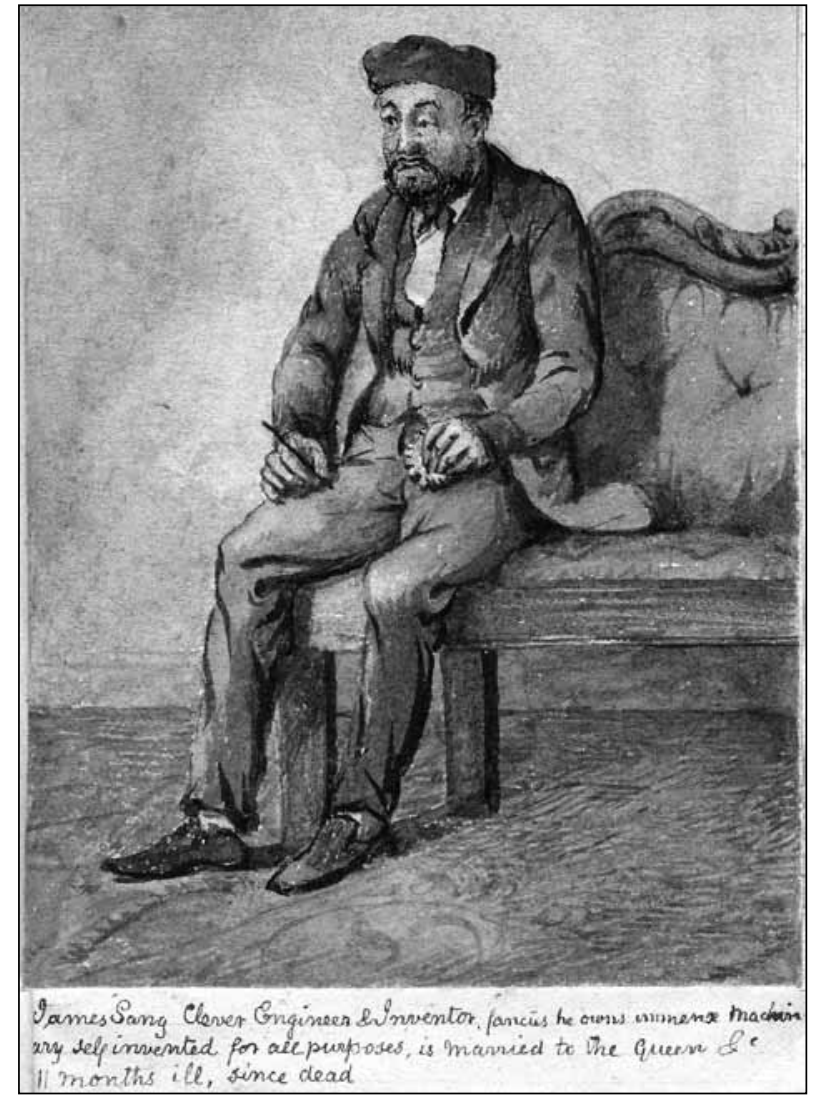

FIGURE I Sketch of an REA general paralytic patient, 'bruised reeds' watercolour series, c. 1880-2 (courtesy of The Royal College of Physicians of Edinburgh).

notably the dementia patient, generally approached death devoid of their humanity and exuberance for life - the so-called 'living death' of dementia - and were often, mercifully, in the twilight years of their lives. For the general paralytic there were no such consolations. He alone approached certain death in his prime and full of joie de vivre.

A series of watercolour sketches of the REA patient population portrayed the major diseases encountered in the asylum. The general paralytic portrayed in Figure $I$ is of the 'classic' grandiose type. While it was difficult for such artistic representations of the general paralytic to capture effectively the element of self-satisfaction and grandiosity, the description underneath helps. The patient imagines that he invents and owns important machines and is married to the Queen. The sketch takes as its subject a well-dressed, professional man, a 'clever engineer' in the prime of his working life. Pictured with the tools of his trade in hand, the contrast between his previous professional abilities and newfound childlike delusional optimism heightens the tragedy. A search for the patient's case notes suggests that this was a 44-yearold single civil engineer admitted to the REA in January $188 \mathrm{I} .^{29} \mathrm{He}$ is described upon admission as a man of good education who has always been very temperate and abstemious'. Progress notes depict him as 'quiet and inoffensive' but '[e]ternally... full of self-satisfaction and mild benevolence', and increasingly 'feeble in body' and 'stupid in behaviour'. The patient died in October 1882, 21 months after admission, after a series of congestive attacks. While not all GPI patients were considered quite so socially respectable ${ }^{30}$ the loss of a large proportion of patients per annum - especially of such socioeconomic standing - can have done little for the asylum's reputation as a curative institution and little for the morale of the asylum physicians.

\section{DEATH AND THE DIAGNOSTIC PROCESS}

When a patient was admitted to the asylum, diagnosis was not always straightforward. The diagnostic process within the REA can be broken down into three separate components. First, patients received a provisional diagnosis, recorded in the general register of admissions. Second, patients had a 'disease' recorded in their case notes which could differ from their admission register diagnosis. This case note diagnosis might also be scored out and replaced with something else, indicating a revision in medical thinking. Finally, those patients who died in the asylum often received a post-mortem diagnosis relating to their cause(s) of death.

Since the medical background to diagnostic decisions was not always recorded, it can be difficult to establish at what point a patient was assigned to a specific diagnostic category. However, it is clear that diagnosis was not a static process, but ever changing as the patient progressed through their asylum stay. While this is less important for some diseases, it is of crucial importance to GPI, which could resemble a range of other disorders due to its profusion of symptoms. Crucially, the disease's distinctive physical symptoms were often 'absent, or ambiguous, or slight' during its early stages, 'leaving the alienist initially with merely the mental symptoms', thus making initial diagnosis problematic. ${ }^{31}$ Differential diagnosis was often employed in an attempt to distinguish GPI from a range of other afflictions. For Clouston, chronic alcoholic insanity and GPI exhibited particular parallels in terms of aetiology and symptoms, only separated by the alcoholic's typical recovery. ${ }^{32}$ The other common differentials of GPI were dementia, mania and melancholia, though these patients generally lacked the somatic signs of the later general paralytic such as muscular tremors and speech defects. As George Robertson cautioned, 'no one is justified in diagnosing a case of general paralysis from the mental symptoms alone. It is practically impossible to do so; you may suspect it, but you cannot diagnose it with any certainty. Any one who attempts to do so will, sooner or later, come a cropper'. ${ }^{33}$ 
Indeed, a detailed analysis of REA case notes reveals that a significant number of patients were diagnosed initially with another mental condition, most commonly mania or melancholia, and that this was only revised upon the patient's death when the post-mortem revealed the morbid appearances of GPI. Many of the admission certificates of these patients lack mention of 'physical' symptoms, with a focus instead on 'mental' symptoms such as delusions, restlessness and incoherence. However, the notion of 'final diagnosis' is crucial here. The majority of REA patients who received a final diagnosis of GPI exhibited a common set of characteristic mental and physical symptoms by the end of their asylum stay. Indeed, alienists may have long suspected that a patient had GPI but felt unable to alter their diagnosis until the physical symptoms developed or pathological proof was obtained. Alternatively, later physical symptoms, in particular the characteristic seizures which often afflicted patients in the final throes of the disease, inspired physicians like Robertson to search for the other physical symptoms of GPI and to alter the patient's diagnosis at post-mortem. ${ }^{34}$ In short, a confident diagnosis often could not be given until the final stages of the disease, with death confirming the diagnosis.

Death played a dual role in the diagnosis of GPI. Its near certain fatality encouraged pathologists to search for firm post-mortem diagnostic evidence. However, its hopeless prognosis also inspired reluctance in some alienists to pass this 'death sentence' upon asylum patients by so diagnosing during life. Even where a patient seemed to have all the characteristic symptoms, in an environment devoid of serious therapeutic options some physicians were wary of labeling the patient a general paralytic. For both of these reasons, we should heed REA physicians' advice that GPI's prevalence was much more accurately judged by an institution's death rate than by its admission rate. ${ }^{35}$

Indeed, the perceived certainty of death made alienists question any GPI diagnosis where that patient did not leave the asylum via the mortuary. In few other diseases did the outcome of stay drive the diagnostic process. Alienists occasionally published reports of patients considered to be classic cases of GPI who had gone on to recover, hence throwing their diagnosis into considerable doubt. Similarly, the case notes of one REA paralytic state that he 'was examined some time ago by Dr John Macpherson who definitely diagnosed GPI, but the diagnosis is now doubtful owing to the marked improvement which has taken place under treatment'. ${ }^{36}$ A patient's recovery was serious grounds for questioning the GPI diagnosis. In a 1928 meeting of the Royal Medico-Psychological Association, the leading discussant stressed that GPI continued to prove fatal 'in approximately $100 \%$ of cases' and that alienists should dispute that diagnosis in any cases which 'improve[d],

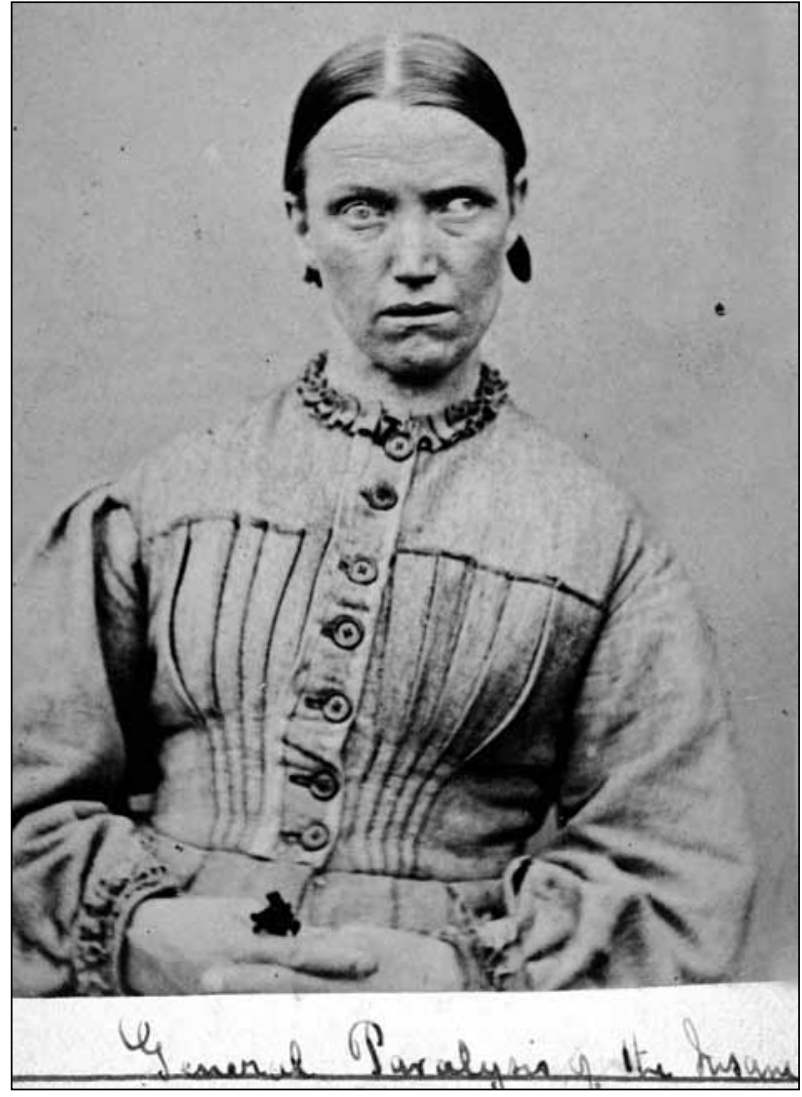

FIGURE 2 Woman suffering from GPI, attributed to Sir James Crichton-Browne, c. 1869 (courtesy of the Wellcome Library, London).

react[ed] to treatment, or remain[ed] stationary for very long periods'. ${ }^{37}$ As Clouston wrote of one patient: 'It may be said that as he has not died it is impossible to say that this is a case of true general paralysis. ${ }^{38}$

Physiognomy, the study of human characteristics and personality based on facial configuration, provided another source of information for the diagnostic process. ${ }^{39}$ During the fin-de-siècle period, Scottish alienists exploited clinical photography to a limited extent. Portrait photographs were inserted into some case notes and served two purposes: as an aide memoire to help identify the patient should they escape, and as a diagnostic tool to assist physicians in diagnosis. ${ }^{40}$ The Edinburgh-born alienist and amateur photographer James Crichton-Browne and the naturalist Charles Darwin corresponded specifically about the clinical value of photographing the general paralytic (Figure 2). ${ }^{41}$ The photo was taken in such a way as to illustrate a number of GPl's key features, including the exalted delusions and expressionless facial appearance.

While those photographs inserted into the REA case notes were almost exclusively of the simple portrait style, one stands out as it depicts something quite different (Figure 3). This image is pasted at the end of the 
case notes of a 50-year-old female general paralytic admitted in December $1894^{42}$ and illustrates the state of her brain at post-mortem upon removal of the skull cap. The patient's case notes reveal no diagnostic confusion from admission onwards: she was described upon arrival as showing a range of clinical signs 'characteristic of G.P.', and at no point does any other diagnosis appear to have been considered.Yet upon her death in January 1897, the photograph seems to have been included in her report because it reveals the classic pathological appearance of GPI in the brain, described in this case as "congested and bloody effusion in front of each ascending frontal convolution'. Around this time, Thomas Clouston's textbook Clinical Lectures on Mental Diseases described the pathological appearance of the general paralytic brain. He noted that the "encasings and supports of the organ' were all affected, that the dura mater was thickened, and that GPI was a disease of the 'outer layer of the cerebral convolutions'. ${ }^{43}$ The 'raw data' for such alienists' textbooks was precisely the patient populations of their asylums. This patient photographed at postmortem must have been felt to be a particularly excellent illustrative example of GPI's pathology.

Post-mortem data had been valued within the REA for some time before this. Under the REA's first physician superintendent William McKinnon (1839-46), a brief summary of pathological data for each death was included in annual reports. In 1840 it was noted that a post-mortem examination was made in five of the six deaths which had occurred in the institution. ${ }^{44}$ Two of these cases were attributed to GPI, with the following data provided in one case:

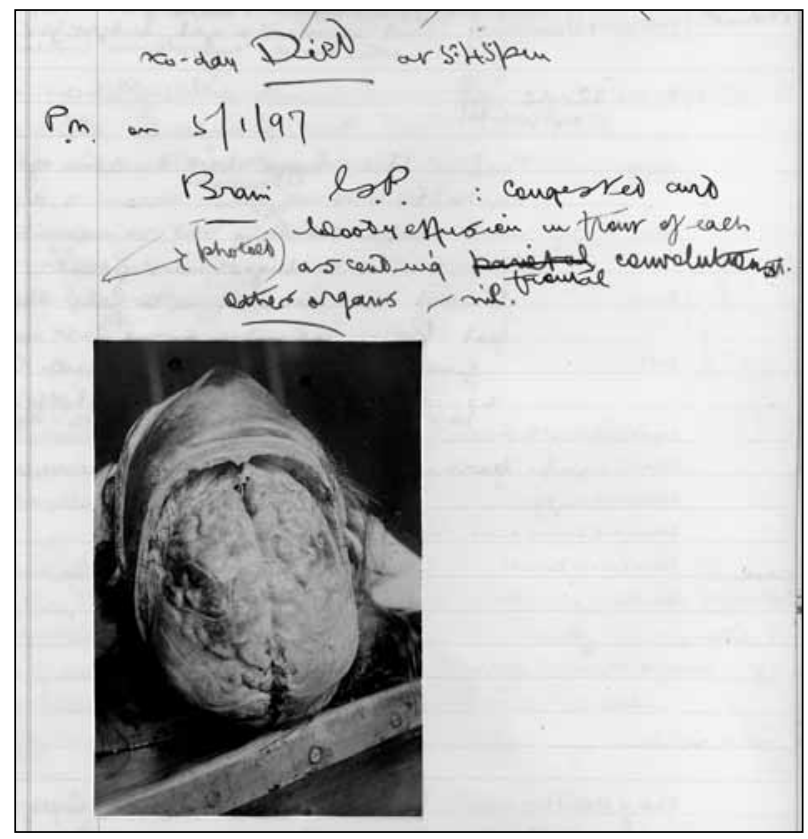

FIGURE 3 Royal Edinburgh Asylum case book (LHB7/5I/62 courtesy of Lothian Health Services Archive, Edinburgh University Library).
Male, 31 , duration of insanity $2 \frac{1}{2}$ years. Form - at first mania, latterly dementia with paralysis. Cause of death - gp. Morbid appearances within the head general opacity of the arachnoid membrane, with copious effusion of turbid serum into the subarachnoid cellular tissue, giving a white and gelatinous appearance to the surface of the brain when exposed. Lateral ventricles distended with serum.

In a period where no more than 20 deaths occurred per annum, the inclusion of such data in the annual reports was a feasible exercise. Under McKinnon's successor, David Skae, asylum deaths were to reach a peak of 93 per annum, making the routine inclusion of such data impractical. Nonetheless, there remained a desire to conduct post-mortems wherever possible, as evidenced by the inclusion of post-mortem data in the case notes of many deceased patients. The compilation of such data would have helped Skae to build up a picture of the pathological appearance of GPI. Thus in print he confidently described 'the bodies of those who ha[d] died' of the disease as generally exhibiting 'chronic inflammatory action in the membrances of the brain, consisting in thickening and milky opacity of the arachnoid membrane, a gelatinous thickening of the pia mater, or serous effusion into the sub-arachnoid cellular tissue or pia mater... in short, a general atrophy of the brain'. ${ }^{13}$

Institutional enthusiasm for pathological research continued to grow under the physician-superintendency of Thomas Clouston. A summary of post-mortem findings were often included in the patient's case notes, as seen in Figure 3. In the case book from which this image is reproduced, while the majority of patients were discharged home or transferred, 30 died. Of these, postmortem data for 25 patients is transcribed into their case notes, suggesting that post-mortems had become a routine part of asylum medicine; and for three it is explicitly noted 'PM refused', indicating that asylum officials were attempting to obtain consent from relatives and friends and respecting the wishes of those who objected. Praise for the REA's pathological endeavours was a regular feature of the Commissioners in Lunacy's biannual reports. ${ }^{45}$ In 1891, Sir Arthur Mitchell noted:'no opportunity is lost of advancing the knowledge of insanity by examination after death. ... The records of pathological work in the Asylum have long been full, and they are constantly and diligently discussed and studied. ${ }^{46}$

In 1893, Dr William Ford Robertson was appointed resident pathologist to the REA and was to make a significant contribution to the pathology of insanity, including the aetiology and pathology of $\mathrm{GPI}{ }^{47}$ Indeed, Ford Robertson wrote one of the earliest Scottish psychiatric textbooks on pathology, A Textbook of Pathology in Relation to Mental Diseases (1900), which remained the standard work of reference on the subject 
at the time of his death in 1923. The textbook included a chapter detailing how post-mortem examinations should be conducted, in which he reproduced the form recently introduced to the REA for pathologists to record their detailed findings. Once these forms were completed, they were bound into volumes, two of which are still extant (REA pathological records). It was presumably with the aid of such work that Ford Robertson's textbook was able to detail so comprehensively the pathological anatomy of the general paralytic. ${ }^{48}$ This may also explain why the earlier of the two extant volumes of the REA's pathological registers (1879-88) contains detailed post-mortem notes on each part of the body, but - in the case of GPI deaths - little that the pathologist appeared to find indicative of or significant about GPI; whereas the later volume (I9II-5) speaks more confidently of the 'typical G.P. brain' ${ }^{49}$

Soon after Ford Robertson's appointment to the REA, to further what Clouston described as the 'splendid original work of enduring importance' being conducted in the asylum's Pathological Department, ${ }^{50}$ the first Scottish asylum laboratory was established in 1897. The Scottish Asylums' Pathological Scheme, inspired by similar endeavours in Germany, America and England, was funded principally by the REA, with Ford Robertson appointed Laboratory Superintendent. The Scheme was founded to unite Scottish asylums in pathological research and to bring science 'to bear on the study of diseased brain and mind' ${ }^{51}$ In fact, in its first decade the laboratory's 'principal object of research' was to elucidate 'the essential pathology' of GPI. ${ }^{18}$ Clouston perhaps wished to devote significant resources to this cause because the REA had the highest proportion of general paralytics in any Scottish asylum. His enthusiasm for the laboratory may also have been related to his belief that: 'When we know fully the pathology of [GPI] and that of epilepsy, we shall be very near the solution of the chief problems of mental disease'. ${ }^{52}$ Thus, while 'silting up' the Victorian and Edwardian asylum, the general paralytic may also have acted as a catalyst to Scotland's embracing of the neuropsychiatric tradition.

\section{CONCLUSION}

General paralysis of the insane was widely held to be the 'one absolutely hopeless disease' of the nineteenthcentury asylum, 'which, being once recognised, the patient's doom [was] held to be sealed'. ${ }^{53}$ The cruelty of the disease was exacerbated by the relatively youthful and industrious patient population that it targeted, the sheer numbers afflicted and the speed with which victims were reduced to profound mental and physical incapacity. The final cruelty was the fact that the general paralytic's physical and mental degradation occurred amidst so much imaginary power and grandeur. For alienists such as Skae, there was no more pathetic sight within the asylum than general paralytics, 'arrested suddenly in the height of prosperity' and doomed to degenerate 'into a state of hopeless fatuity' before dying 'far beyond the reach of friendly consolation'. ${ }^{3}$ The rapid decline and certain death of physically able and socially worthy patients on such a grand scale was surely one of the greatest tragedies of the asylum.

The certainty of death was central to the diagnostic process surrounding GPI. A significant proportion of those REA patients diagnosed as general paralytic attracted that diagnosis only at post-mortem. This was due in part to the polymorphous symptomatology associated with the disease and, in particular, the relatively late development of the characteristic somatic symptoms which truly distinguished the disease from its common differentials. However, the hopeless prognosis may have acted as a disincentive to diagnose GPI until the final characteristic symptom presented itself: death. Indeed, a GPI diagnosis was subject to serious scrutiny on the rare occasion that the patient did not ultimately display this symptom. In few other diseases can the outcome of stay be observed to have shaped the diagnostic process so fully.

There can be no doubt that GPI was a deeply troubling disorder to the alienist who possessed nothing in his therapeutic arsenal with which to combat the disease. During a period of pronounced pessimism over seemingly spiralling numbers of insane and the therapeutic failure of psychiatry, the high admission and death rates attributed to a uniformly fatal disorder can only have been bad news. This was particularly the case for the REA, an institution that had a higher proportion of general paralytics than any other Scottish asylum. However, the REA was also the largest and most prestigious of Scottish asylumdom, the 'Edinburgh School of Psychiatry' having been portrayed as a thriving site of psychiatric intellect and practice. ${ }^{54}$ Thus, if any institution could capitalise upon such a deadly disorder, it was surely the REA, by transforming the paralytic into valuable pathological material and embracing the German neuropsychiatric tradition.

\section{Acknowledgements}

Sincere thanks are due to Jonathan Andrews, Mike Barfoot, Roger Davidson, David Wright and the staffs of the Lothian Health Services Archive and the Royal College of Physicians of Edinburgh Library. 


\section{REFERENCES}

I Brown E. French psychiatry's initial reception of Bayle's discovery of general paresis. Bull Hist Med 1994; 68:235-53.

2 Hare E. The origin and spread of dementia paralytica. J Ment Sci 1959; 105:594-626.

3 Esquirol ]. [Des maladies mentales considerees sous les rapports medical, hygienique et medico-legal.] Paris: J Bailliere; 1838. p. 439. French.

4 Conolly J. Clinical lectures on the principal forms of insanity. The Lancet I846; I:233-7. http://dx.doi.org/I0.I0I6/S0I40. 6736(02)89765-3

5 Noguchi H, Moore J. A demonstration of treponema pallidum in the brain in cases of general paralysis.J Exper Med 1913; 17:232-8. http://dx.doi.org/I0.1084/jem.17.2.232

6 Davis G. 'The cruel madness of love': sex, syphilis and psychiatry in Scotland, 1880-1930. Amsterdam: Rodopi; 2008. pp. 199-238.

7 Clouston T. How the scientific way of looking at things helps us in our work, 1908. Lothian Health Services Archive (LHSA), Edinburgh University Library, LHB7/I4/8: p. 9.

8 Hurn J.The changing fortunes of the general paralytic. Wellcome History 1997; 4:5.

9 Royal Edinburgh Asylum (REA) annual reports, 1840 and 1908. Lothian Health Services Archive (LHSA), Edinburgh University Library, LHB7/7/6-12.

10 Whitrow M. Julius Wagner-Jauregg, 1857-1940. London: SmithGordon; 1993.

I I Braslow J. Mental ills and bodily cures: psychiatric treatment in the first half of the twentieth century. Berkeley: University of California Press; 1997.

12 Hurn J. The history of general paralysis of the insane in Britain, 1830 to 1950 [PhD thesis]. University of London; 1998. p. 40.

13 Skae D. Contributions to the natural history of general paralysis. Edin Med J 1859-1860; 5:8856-9053.

14 Tuke H. On general paralysis.J Mental Sci I859; 6: 79-93; I98-205.

15 Skae D, Clouston T. The morisonian lectures on insanity for 1873 . J Mental Sci 1875; 21:189-204.

16 Blandford G. Insanity and its treatment. Edinburgh: Oliver and Boyd; 187I. pp. 286-7.

17 Clouston T. Unsoundness of mind. London: Methuen; I91 I:pp. 243-5.

18 Ford Robertson W. The pathology of general paralysis of the insane. Rev Neur Psych 1906; 4:73.

19 Hurn J. The history of general paralysis of the insane in Britain, 1830 to 1950 [PhD thesis]. University of London; 1998. p. 273.

20 Robertson G. The morison lectures, 1913.J Mental Sci 1913; 59. pp. |85-221.

21 Hare E. Was insanity on the increase? $\mathrm{Br} J$ Psychiatry 1983; |42:439-55. http://dx.doi.org/ I0.1 192/bjp. |42.5.439

22 Scull A. The most solitary of afflictions: madness and society in Britain, 1700-1900. New Haven:Yale University Press; 1993. pp. 352-5.

23 Davis G. 'The cruel madness of love': sex, syphilis and psychiatry in Scotland, 1880-1930. Amsterdam: Rodopi; 2008: pp. 227-8.

24 Royal Edinburgh Asylum annual report, 190I. Lothian Health Services Archive (LHSA), Edinburgh University Library, LHB7/7/I0.

25 Robb J. Review of Balado and Esteves.J Mental Sci 1930; 76:358.

26 Clouston T. Clinical lectures on mental diseases. London: J\&A Churchill; 1896. p. 378.

27 Royal Edinburgh Asylum case book. Lothian Health Services Archive (LHSA), Edinburgh University Library, LHB7/5 I/57.

28 Royal Edinburgh Asylum case book. Lothian Health Services Archive (LHSA), Edinburgh University Library, LHB7/5 I/70.
29 Royal Edinburgh Asylum case book. Lothian Health Services Archive (LHSA), Edinburgh University Library, LHB7/5I/36, 38.

30 Davis G. 'The cruel madness of love': sex, syphilis and psychiatry in Scotland, 1880-1930. Amsterdam: Rodopi; 2008. pp. 21 I-30.

3I Mickle W. General paralysis of the insane. London: HK Lewis; 1886. p. 217.

32 Clouston T. Unsoundness of mind. London: Methuen; I9I I. p. 246.

33 Robertson G. Clinique on general paralysis, 1920. Lothian Health Services Archive (LHSA), Edinburgh University Library, GDI6.

34 Robertson G. Clinique on general paralysis, 19/8. Lothian Health Services Archive (LHSA), Edinburgh University Library, GDI6.

35 Royal Edinburgh Asylum annual report, 1908. Lothian Health Services Archive (LHSA), Edinburgh University Library, LHB7/7//2.

36 Royal Edinburgh Asylum case book. Lothian Health Services Archive (LHSA), Edinburgh University Library, LHB7/5 I/I 08.

37 Discussion. General paralysis.J Mental Sci 1929; 75:25.

38 Clouston T. Clinical lectures on mental diseases. London: J\&A Churchill; I883. p. 37I.

39 Jordanova L.The art and science of seeing in medicine: physiognomy I780-1820. In: Bynum W, Porter R editors. Medicine and the five senses. Cambridge: Cambridge University Press; 1993.

40 Burrows A, Schumacher I. Portraits of the insane: the case of $\mathrm{Dr}$ Diamond. London: Quartet Books; 1990.

4I Browne J. Darwin and the face of madness. In: Bynum W, Porter R, Shepherd $M$ editors. The anatomy of madness, vol one. London: Tavistock; 1985.

42 Royal Edinburgh Asylum case book. Lothian Health Services Archive (LHSA), Edinburgh University Library, LHB7/5I/62.

43 Clouston T. Clinical lectures on mental diseases. London: J\&A Churchill; 1896. p. 404; p. 4 I5.

44 Royal Edinburgh Asylum annual report, 1840. Lothian Health Services Archive (LHSA), Edinburgh University Library, LHB7/7/6.

45 Andrews J. "They're in the trade... of lunacy, they 'cannot interfere'they say": the Scottish lunacy commissioners and lunacy reform in nineteenth-century Scotland. London: Wellcome Institute for the History of Medicine; 1998.

46 Royal Edinburgh Asylum annual report, 1891. Lothian Health Services Archive (LHSA), Edinburgh University Library, LHB7/7/9.

47 Davis G. The cruel madness of love': sex, syphilis and psychiatry in Scotland, 1880-1930.Amsterdam: Rodopi; 2008. p. 147.

48 Ford Robertson W. A textbook of pathology in relation to mental diseases. Edinburgh:William Clay; 1900. pp. 344-55.

49 Royal Edinburgh Asylum pathological records. Lothian Health Services Archive (LHSA), Edinburgh University Library, LHB7/43/I-2.

50 Royal Edinburgh Asylum annual report, 1895. Lothian Health Services Archive (LHSA), Edinburgh University Library, LHB7/7/I0.

5I Royal Edinburgh Asylum annual report, 1898. Lothian Health Services Archive (LHSA), Edinburgh University Library, LHB7/7/I0.

52 Clouston T. Clinical lectures on mental diseases. London: J\&A Churchill; 1896. p. 404.

53 Royal Edinburgh Asylum annual report, 1876. Lothian Health Services Archive (LHSA), Edinburgh University Library, LHB7/7/8.

54 Andrews J.A failure to flourish? David Yellowlees and the Glasgow school of psychiatry. Hist Psychiatry 1997; 8: 177-2 12. http://dx.doi. org/I0.II77/0957/54X970080300। 